\title{
Clustering Poverty Incidence Based on Social Indicators
}

\section{Ed Neil Maratas*}

\begin{abstract}
Poverty is known as one of the main problems in the Philippines for many decades. This study attempted to classify, cluster, and evaluate the common incidence of poverty among the municipalities of Zamboanga del Norte based on social indicators. It used a hierarchical approach to decompose complex problems by reducing them to a smaller set of interrelated problems. Data mining, including secondary data released by the Philippine Statistics Authority, the Department of Health National Nutrition Council, the Provincial Police Office, and the Department of Education, has conducted to review broad databases and generate new knowledge. The study found that the top poorest municipalities were located in the third district of the province with less access to drinking water, less access to sanitary toilets, high malnutrition, low literacy rates, less access to safe housing, and a lack of land ownership. Similarly, it was observe that the poverty incidence closely related to the proportion of households without sanitary toilets. Poor health and sanitation of provincial residents could lead to a higher risk of exposure to many diseases. Given the high incidence of poverty in the province top poorest municipalities, it should be noted that provincial and local governments should make concerted efforts to openly improve the "Water, Sanitation and Hygiene (WASH) Program" "Basa Pilipinas Program" "Provision of Potable Water Program" and the "Garantisadong Pambata Program" programs to address the increasing public concern about poverty. In addition, the health and sanitation policy of the national and local governments must be improved and thoroughly monitored to resolve the chronic poverty problem at the municipal and national level in general.
\end{abstract}

Keywords: Clustering Algorithm Analysis, Poverty, Social Indicators, Governance, Health and Sanitation, JRMSU, Dapitan City, Philippines

\footnotetext{
* Jose Rizal Memorial State University. Email: ednielmaratas@gmail.com
} 


\section{INTRODUCTION}

Every nation has the overriding objective of developing efforts, that is, enhancing the quality of life of the people. Poverty and inequality have been a chronic issue in the Philippines and have come to the fore again in the wake of the ongoing global financial crisis and rising food, fuel, and commodity prices experienced several years ago 1 . The Philippines has been committed to the alleviation of poverty for many decades ago. These are goals for human development and poverty reduction seek to reduce poverty in every area of the country.

Despite all those who understand the growth of poverty and formulate different policies and economic development projects to minimize poverty, the government still faces high levels of poverty and hunger among its people ${ }^{2}$. Cruz (2016) of ABS-CBN news reported that due to the impact of calamities some parts of Mindanao have remained unrecovered. The incidence of poverty in the Philippines slowly decreased in the first half of 2015 according to the Family Income and Expenditure Survey (FIES, 2016) conducted by the Philippine Statistics Authority (PSA).Mendoza et al., (2016), noted that the Philippines is home to around one million Filipino families living below the poverty line ${ }^{3}$. In fact, according to the Philippine Statistical Authority (PSA 2015), about 21 percent of Filipinos living in poverty earn less than $\$ 1,982$ a year. Among the top 20 provinces in the country as of 2015, Zamboanga del Norte ranks top 8 with a poverty rate of about 56.1 percent lower than the 2006-2012 poverty rate of about 64.6 percent. ${ }^{4}$

Zamboanga del Norte is situated in Region IX has a land area dedicated to agriculture, that is, maize, coconut, and rice production. In addition, rich in marine and mineral resources, and its production of fish has accelerated through the growth of fishponds. Commercial fishing has also gradually increased over the years (Philippine Information Agency, Z.N. Base). But then again, people living in the province are also not able to get out of poverty. The incidence of poverty in this study is the proportion of poor individuals/families among the population and those whose income falls below the poverty level or who cannot afford to meet their basic needs. Besides, those families with five members with a monthly income of less than Php8, 778 deemed poor families. Poverty in a given region was mainly determined by the results of poverty incidence. ${ }^{5}$

Several initiatives will concentrate on poverty issues in the world. One of these is the recognition of the incidence of poverty at the local and regional level. Identifying a range of indicators that contribute more to the incidence of poverty is important for the preparation of policy papers on poverty problems and policy alternatives. The national government recognized the need for sustainability and frequent updates of poverty estimates, especially at the municipal levels. ${ }^{6}$ It is intended primarily to provide input and guidance to local government units, policymakers, and program implementers in the implementation of poverty-reduction action programs. To optimize the effectiveness of any poverty alleviation program, certain variables must be carefully considered before implementation. That is, the proper identification of priority areas is one of the most common considerations.

1 Development Bank, A. Poverty in the Philippines Causes, Constraints, and Opportunities, (2009)

2 Ibid.,

3 Mendoza, A., C. Cajarville, and J. L. Repetto. "Digestive response of dairy cows fed diets combining fresh forage with a total mixed ration." Journal of Dairy Science 99, no. 11 (2016): 8779-8789.

4 Philipine Statistics Authority. 2015 Full Year Official Poverty Statistics of the Philippines. (2016), 43

5 Gavino-Gumba, Bernadette M. "The social and economic dimensions of rural poverty in the province of masbate." (2010)

6 Ibid., 
As a result, this paper attempted to examine and group related poverty incidence in Zamboanga del Norte with the aid of a clustering algorithm approach. The researcher also exploring what problems can be extracted from clustering regions in terms of poverty incidence, demographics, health, and sanitation, education, housing, land tenure, and governance. The researcher has integrated a cluster analysis approach to counter this phenomenon. Cluster analysis is a technique used to group related observations into several clusters based on the observed values of several variables for each entity. Maximizes the similarity of cases within and cluster while maximizing the dissimilarity between initially unknown classes. This will use the hierarchical algorithm technique of the cluster.

\section{Theoretical Framework}

This research is based on the Classical Traditions Theory adapted from the article by Davis \& Sanchez-Martinez, (2014) entitled "A Review of the Economic Theories of Poverty." This article considers individuals to be solely responsible for their fate and, besides, chose to become poor (e.g. by creating single-parent families) ${ }^{7}$. The definition of 'poverty subcultures' suggests that shortcomings which persist over time due, for example, to the lack of suitable role models and that government assistance should be restricted to changing individual capacities and attitudes (i.e. the laissez-faire tradition). Another hypothesis is the Neoclassical theories, which are more comprehensive and consider causes for poverty outside the control of individuals. These include a lack of both social and private assets; market failures that exclude disadvantaged people from credit markets and make some adverse choices rational; barriers to education; immigrant status; poor health and advanced age; and barriers to jobs for single-parent families.

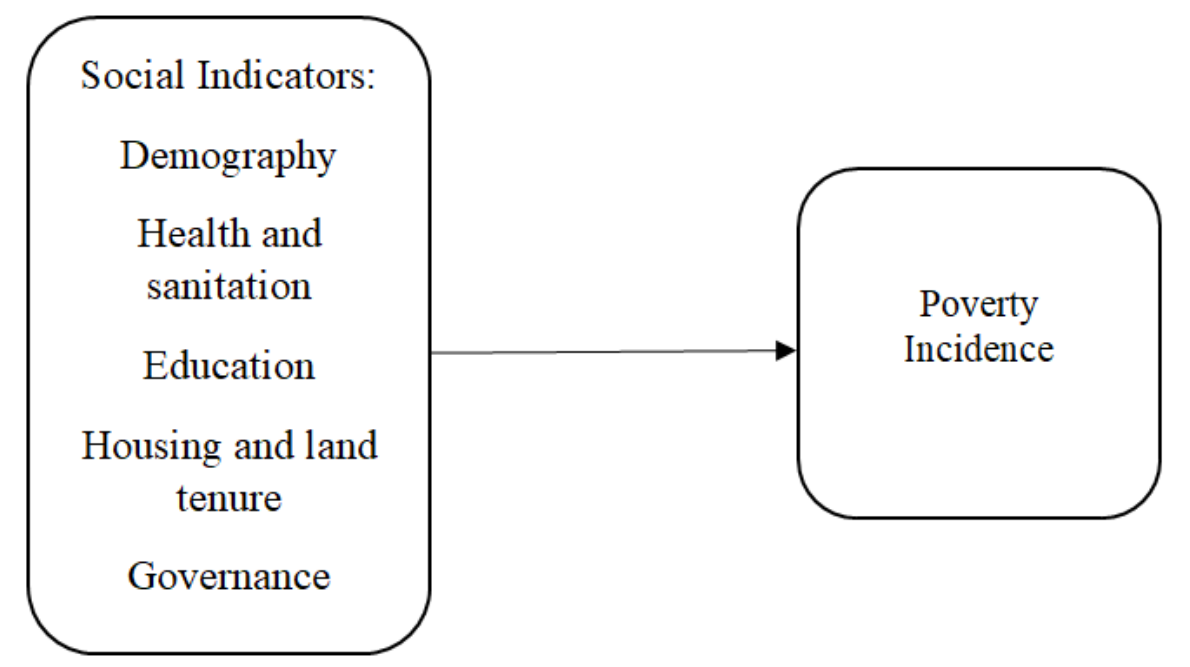

Figure 1: Conceptual Framework

The Gavino-gumba, (2013) study argues that poverty studies are some of the research subjects that are mainly on the list of government and institutions around the world ${ }^{8}$. The researcher has

7 Davis, E. Philip, and Miguel Sanchez-Martinez. Economic theories of poverty. Joseph Rowntree Foundation, 2015.

8 Gavino-Gumba, Bernadette M. "Fiscal Management and the Bicol Autonomous Region in the Philippines." Research and Applications in Economics 2 (2014): 39-43. 
found out that poverty has risen dramatically to include economic and social indicators. Social measures include education, sanitation, access to clean water for electricity, school enrolment rates, access to health care, mortality, access to land, and involvement in decision-making, infrastructure, and market access. ${ }^{9}$

This paper identified the status of poverty in the Province of Zamboanga del Norte. The study sought to determine which of the municipalities have commonalities in terms of poverty incidence, demography, health and sanitation, education, housing and land tenure, and governance. Lastly, to determine the social indicators that relate to the poverty incidence in the Province of Zamboanga del Norte.

\section{MATERIALS AND METHODS}

The researcher used data mining techniques and a correlational analysis tool. Primary data is the primary source of knowledge. Data mining is a method of looking at broad knowledge banks to produce new information. It is all about extrapolating trends and new insights from the data collected. Datasets is from the various agencies that have recently released web-based 2012 reports on the listed variables used in the analysis. The following departments are the Zamboanga del Norte Department of Education, the National Statistics Office, the most recent Population and Housing Survey, the National Mapping and Resource Information Authority, the Health Nutrition Council Department, and the Zamboanga del Norte Provincial Police Office. This study includes demography (population and household number); health and sanitation (proportion of households with no access to drinking water, no sanitary toilets and percentage of undernourished children; education (literacy); housing and land tenure (proportion of households owned and owned by a lot); and Peace Governance (Estimated Crime Rate). After the preparation of the results, Cluster and Regression analysis carried out with the support of statistical package for social sciences (SPSS) software. Cluster analysis was use to group municipalities according to the variables used in the report. While regression analysis is, a confirmatory analysis approach attempted to establish if the poverty incidence and the various social indicators are linearly correlated.

\section{RESULTS AND DISCUSSION}

After the data collection, the researchers' next step is to present and discuss the result of the target objectives of the research.

\section{Status of Poverty}

The distribution of the poverty rate of twenty-five (25) municipalities and two (2) cities are shown in Figure 1. Each of the three districts has a share of municipalities and towns. District 1 consists of municipalities and cities such as Dapitan City, La Libertad, Mutia, Pinan, Polanco, Rizal, Sergio Osmeña, and Sibutad. The following municipalities and cities are located in District 2, namely: Dipolog City, Jose Dalman, Katipunan, Manukan, Roxas, Sindangan, and Siayan. District 3 consisting of 12 municipalities: Salug, Baliguian, Godod, Gutalac, Kalawit, Labason, Leon Postigo, Liloy, Sibuco, Siocon, Sirawai, and Tampilisan.

9 Deichmann, Uwe. "Geographic aspects of inequality and poverty." Roma: FAO (1999) 
JHSS, Vol. 11, No. 2, July to December, 2020

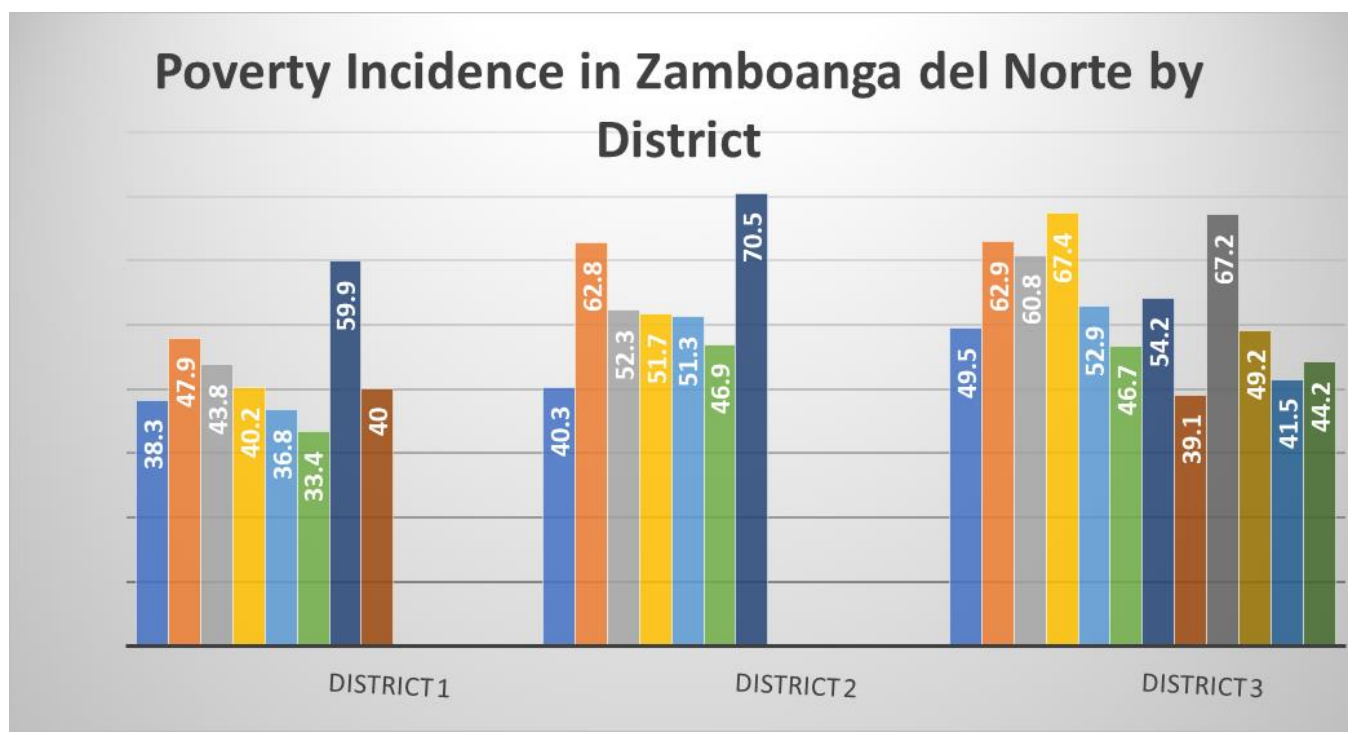

Figure 1. Graphical Presentation on Poverty Incidence of Zamboanga del Norte by District Source:https://psa.gov.ph/sites/default/files/ZAMBOANGA\%20DEL\%20NORTE_FINAL\%20PDF.pdf

Based on the figure, the top five poorest municipalities in the province of Zamboanga del Norte are Siayan (70.5), Gutalac (67.4), Sibuco (67.2), Baliguian (62.9), and Jose Dalman (62.8). The data reveals that the majority of the poorest municipalities are located in District 3 of the province. It can be inferred, that, 67.4 percent of the household population of Gutalac live below the poverty line, which means there are about 67 households for every 100 households that are poor in the said municipality. This also indicates that the cost of living in the top poorest municipalities was comparatively low compared to other places in Zamboanga del Norte. This finding concurred that the highest incidence of poverty was recorded in the municipality of Siayan in 2003 (97.5 percent) and 2009 (79.86 percent).

While there was a small decrease in the incidence of poverty in the Municipality of Siayan in 2012, data still showed a substantial decline in the status of poverty in Zamboanga del Norte. The local government must therefore take full action to revisit and improve the poverty alleviation programs established in the province, especially for those households living below the poverty line in the municipalities as mentioned above.

In general, mostly (40.7\%) of the municipalities were registered at higher poverty incidence as compared to the poverty threshold in the province. This means that there are more disadvantaged households in Zamboanga del Norte who are unable to afford their basic food and health needs due to poverty and cannot be engaged in economic activities. Given the very high incidence of poverty reported, needless to mention that national and local governments should make a concerted effort to improve measures to resolve the public concern about poverty.

Maratas, et al., (2014) confirmed the present findings, which have shown that the bulk of the poorest municipality in the province is mainly from the third (3rd) district in the province of Zamboanga del Norte ${ }^{10}$. Development Bank (2009) emphasizes that poverty tends to be a

10 Maratas, Ed Neil. "Clustering Poverty Incidence Based on Social Indicators." Journal of History and Social Sciences 11, no. 2 (2020) 
predominantly rural problem, with urban poverty on the rise ${ }^{11}$. This means that the majority of the poor are still living in rural areas and the agricultural sector, mostly as farmers and fishers.

\section{Clustering of Municipalities using Hierarchical Clustering Algorithm}

Municipalities tend to be divided into similar characteristics of poverty incidence, which are relatively homogeneous. Table 1 presents clusters of municipalities with related incidences of poverty and social indicators. The municipalities are divided into three dimensions with the aid of cluster analysis. Using the squared Euclidean distance and single linkage, and after the amalgamation steps, the final partition revealed two (2) Cluster 1 municipalities, one (1) Cluster 2 municipalities, and twenty-four (24) Cluster 3 municipalities. It is expressed in the table that the majority of municipalities in Cluster 3 are the top poorest municipalities in the province. This means that the province of Zamboanga del Norte is still on the list of the most consistent poorest provinces to date. This is because groups of municipalities with a higher rate of poverty have distant barangays. This would result in less access for households to economic engagement to support their everyday needs. The Television Channel, ABS-CBN News, (2015), recorded that the persistently high incidence of poverty among Filipino families in rural areas was due to a rapid rise in market prices. Besides, Arsenio Balisacan, Secretary of Economic Planning, stressed that the government needs to reform the expenditure components of poverty reduction programs to balance the price movements and incomes of the poor.

Table 1. Group of Municipalities/City with Common Poverty Incidence

\begin{tabular}{|c|c|c|}
\hline Cluster 1 & Cluster 2 & Cluster 3 \\
\hline Dapitan City & Dipolog City & Polanco, Rizal, Katipunan, Jose Dalman, La \\
Sindangan & Libertad, Sibutad, Piñan, Sergio Osmeña, \\
& Mutia, Manukan, Roxas, Salug, Baliguian, \\
& Godod \\
& Gutalac, Kalawit, Labason, Leon Postigo, \\
& Liloy, Siayan, Sibuco, Siocon \\
& Sirawai, Tampilisan \\
\hline
\end{tabular}

\section{Municipalities have Commonalities in terms of Poverty Incidence and Social Indicators}

Table 2 indicates the cluster of municipalities with a common incidence of poverty and social indicators. This table was further set out in the result of Table 1 . Both clusters 1 and 2 have a lower rate of poverty compared to cluster 3 based on the grand centroid. Cluster 3 includes a set of municipalities with a very high rate of poverty and has a higher proportion of households with no sanitary toilets, a high level of violence, a lower level of property, a low level of access to drinking water, a high percentage of undernourished children and a low level of literacy. The incidence of poverty is, as predicted, associated with household educational attainment. The size of the family is also positively associated with the incidence and vulnerability of poverty (Development Bank, 2009).

11 Op.Cit. Poverty in the Philippines Causes, Constraints, and Opportunities. (2009) 
JHSS, Vol. 11, No. 2, July to December, 2020

Table 2. Cluster Centroids of the Municipalities with |Common Poverty Incidence

\begin{tabular}{|c|c|c|c|c|}
\hline Variable & Cluster1 & Cluster2 & Cluster3 & Grand Centroid \\
\hline Poverty Incidence & 42.6000 & 40.3000 & 51.0917 & 50.0630 \\
\hline Population & 90926.5000 & 130759.0000 & 29115.8750 & 37459.0000 \\
\hline No. Household & 18287.5000 & 26418.0000 & 5931.0417 & 7605.1111 \\
\hline HH No Access safe Water & 0600 & 0.0200 & 0.1657 & 0.1524 \\
\hline HH with No Sanitary Toilet & 0.1150 & 0.0200 & 0.1913 & 0.1793 \\
\hline Malnourished Children & 7.8450 & 1.8000 & 9.6900 & 9.2611 \\
\hline Crime Rate & 0.1930 & 0.2900 & 0.3333 & 0.3213 \\
\hline Own housing Unit & 0.2100 & 0.2200 & 0.2141 & 0.2140 \\
\hline With Lot Owned & 0.5250 & 0.5900 & 0.5708 & 0.5681 \\
\hline Literacy Rate & 95.6650 & 99.0000 & 75.9225 & 78.2396 \\
\hline
\end{tabular}

Legend: HH-Household: No. - Number

The data shows that if the municipality has a lower number of households sent to school and low access to drinking water, the rate of poverty rises. In addition, most of the children in Cluster 3 have not been provided with adequate nutrition for a safe and well-nourished lifestyle. This is because they live in isolated rural parts of the province. Crime cases conducted along the fuses of municipalities have also been prevalent. Since most municipalities in the group are controlled and recognized as the home of insurgent groups (ISIS and the rebel group). Thus, without coping with these barriers of poverty in a certain municipality, the household will continue to be poor in the city.

\section{Indicators Relate to the Poverty Incidence}

Regression analysis produces an equation to explain the statistical relationship between one or more predictor variables (social indicators) and the response variable (poverty incidence) using statistical tools. A regression analysis between the incidence of poverty and social indicators is provided in Table 3. Looking at the p-value of the t-test for each predictor variable, it can be shown that a household without a sanitary toilet $(\mathrm{p}=0.011<0.05)$ of a municipality contributes significantly to the model, but others do not. This can be concluded that sanitation is a major factor in the prevention of every disease in any human being. It can be interpreted that, for every household without a sanitary toilet in the locality, the incidence of poverty is 40.69 percent, with other variables constant. Sanitary toilets are necessary to unlock the social and economic development of society to save the lives of thousands of children. This is also very important for the survival and growth of people around the world, as exposure to human waste causes disease (WHO/UNICEF, 2008). According to Roberts (2018), the bad health post, in turn, traps communities in poverty. Infectious and untreated tropical diseases destroy and weaken millions of the poorest and most vulnerable people every year.

Predictors such as the percentage of undernourished children $(\mathrm{p}=0.055)$, the proportion of households without access to safe water $(p=0.084)$, and the literacy rate $(p=0.075)$ have almost contributed to the incidence of poverty in the province of Zamboanga del Norte. There is a small difference between $\mathrm{p}$-value and significance level (0.05), which is a clear indication that variables are predictors of the prevalence of poverty. 
Table 3. Regression Analysis between Poverty Incidence and Social Indicators

\begin{tabular}{|c|c|c|c|c|}
\hline Predictor & Coef & SE Coef & T & P \\
\hline Constant & 52.88 & 29.49 & 1.79 & 0.09 \\
\hline Population & 0.00007222 & 0.00005399 & 1.34 & 0.198 \\
\hline $\begin{array}{c}\text { HHnoAcc_safe } \\
\text { water }\end{array}$ & 24.97 & 13.63 & 1.83 & 0.084 \\
\hline HHw NO Toilet & 40.69 & 14.28 & 2.85 & 0.011 \\
\hline Percent Mal_child & 0.6328 & 0.3084 & 2.05 & 0.055 \\
\hline Crime Rate & 11.15 & 16.4 & 0.68 & 0.505 \\
\hline With house Own & -111.84 & 97.88 & -1.14 & 0.268 \\
\hline With lot own & 18.05 & 20.41 & 0.88 & 0.388 \\
\hline Literacy Rate & -0.1583 & 0.08384 & -1.89 & 0.075 \\
\hline
\end{tabular}

Legend: HHnoAcc - Household with no Access: HHw - Household with Mal - Malnourish: $S=5.639 \quad R-S q=79.3 \% \quad R-S q(a d j)=70.1 \%$

Looking at the R-squared value of $79.3 \%$, which is relatively higher, indicates a better model fits the data. This means that overall; the social indicators presented in the model explain $79.3 \%$ of the variations in poverty incidence.

\section{CONCLUSIONS}

Following the presentation of the results, the conclusions are offered. Poor municipalities in the Zamboanga del Norte are dense in the 3rd district, most likely to have less access to drinking water, less access to sanitary toilets, high malnutrition, low literacy rates, less access to safe housing, and a lack of land ownership. Poor households in the province cannot afford their basic needs, food, and health because of poverty and thus cannot maintain their contribution to economic activities. Owing to a lack of awareness, households cannot identify and assert their needs in their day-to-day lives. They are remote from basic facilities, non-governmental agencies, cooperatives, external emergency aid, and lack of communication with government officials. Poor households are continually struggling to afford food and health care, giving them little time or resources to shape or enter organizations to improve their place in society.

The findings of the regression analysis indicate that the incidence of poverty is closely linked to the proportion of households without sanitary toilets, literacy, malnutrition, and access to clean water. This means that inadequate health and sanitation can contribute to a rise in the risk of exposure to many illnesses and diseases and can contribute to the poverty traps of communities. It can also be concluded that the majority of households in the province are still hoping to meet the basic needs of the local government, especially those with a high incidence of poverty.

\section{Recommendations}

The following recommendations are given based on the results presented. Given the high incidence of poverty in the province's top poorest municipalities, it should be noted that provincial and local governments should make concerted efforts to explicitly improve the 
"Water, Sanitation and Hygiene (WASH) Program" "Basa Pilipans Program" "Provision of Potable Water Program" and the "Garantisadong Pambata Program" programs to address the increasing public concern about poverty. The health and sanitation policy of the state and local governments must be improved and thoroughly monitored to resolve the chronic poverty problem at the municipal and national level in general. The national government recognized the need for sustainability and frequent updates of poverty estimates, especially at the regional and municipal levels. Given that the data is minimal and relies solely on the available recent published reports on the Internet, it is recommended that future work is required to strengthen the analysis of the incidence of poverty and its significant factors collected from the primary survey.

\section{Funding Sources}

The Office of the Vice President supported this research study for Research, Development and Extension, Jose Rizal Memorial State University funds. 
Clustering Poverty Incidence Based on Social Indicators

\section{References}

ABS-CBN News. (2015, March). Poverty incidence rises in Philippines | ABS-CBN News. https://news.abs-cbn.com/business/03/06/15/poverty-incidence-rises-philippines

Davis, E. Philip, and Miguel Sanchez-Martinez. Economic theories of poverty. Joseph Rowntree Foundation, 2015.

Deichmann, Uwe. "Geographic aspects of inequality and poverty." Roma: FAO (1999)

Development Bank, A.. Poverty in the Philippines Causes, Constraints, and Opportunities. (2009)

Gavino-Gumba, Bernadette M. "Fiscal Management and the Bicol Autonomous Region in the Philippines." Research and Applications in Economics 2 (2014): 39-43

Gavino-Gumba, Bernadette M. "The social and economic dimensions of rural poverty in the province of masbate." (2010)

Mendoza, A., C. Cajarville, and J. L. Repetto. "Digestive response of dairy cows fed diets combining fresh forage with a total mixed ration." Journal of Dairy Science 99, no. 11 (2016): 8779-8789

Mendoza, R. U., Olfindo, R., \& Maala, C. Spatial Disparities and Poverty: The Case of Three Provinces in the Philippines. SSRN Electronic Journal. (2016). https://doi.org/10.2139/ssrn.2834759

Philipine Statistics Authority. 2015 Full Year Official Poverty Statistics of the Philippines. (2016), 43.

Roberts, S.). Key Facts: Poverty and Poor Health | Health Poverty Action. https://www.healthpovertyaction.org/news-events/key-facts-poverty-and-poor-health/(2018, January 10)

WHO/UNICEF. WHO | Poor sanitation threatens public health. (2008, March 20). https://www.who.int/mediacentre/news/releases/2008/pr08/en/ 